\title{
The impact of anal sphincter injury on perceived body image
}

DOI:

10.1016/j.ejogrb.2017.03.024

\section{Document Version}

Accepted author manuscript

Link to publication record in Manchester Research Explorer

\section{Citation for published version (APA):}

lles, D., Khan, R., Naidoo, K., Kearney, R., Myers, J., \& Reid, F. (2017). The impact of anal sphincter injury on perceived body image. European Journal of Obstetrics Gynecology and Reproductive Biology, 212, 140-143. https://doi.org/10.1016/j.ejogrb.2017.03.024

\section{Published in:}

European Journal of Obstetrics Gynecology and Reproductive Biology

\section{Citing this paper}

Please note that where the full-text provided on Manchester Research Explorer is the Author Accepted Manuscript or Proof version this may differ from the final Published version. If citing, it is advised that you check and use the publisher's definitive version.

\section{General rights}

Copyright and moral rights for the publications made accessible in the Research Explorer are retained by the authors and/or other copyright owners and it is a condition of accessing publications that users recognise and abide by the legal requirements associated with these rights.

\section{Takedown policy}

If you believe that this document breaches copyright please refer to the University of Manchester's Takedown Procedures [http://man.ac.uk/04Y6Bo] or contact uml.scholarlycommunications@manchester.ac.uk providing relevant details, so we can investigate your claim.

\section{OPEN ACCESS}




\section{Accepted Manuscript}

Title: The Impact of Anal Sphincter Injury on Perceived Body Image

Authors: David Iles, Rabia Khan, Kristina Naidoo, Rohna

Kearney, Jenny Myers, Fiona Reid

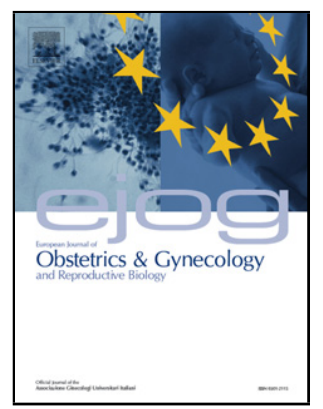

PII: $\quad$ S0301-2115(17)30135-5

DOI: $\quad$ http://dx.doi.org/doi:10.1016/j.ejogrb.2017.03.024

Reference: $\quad$ EURO 9828

To appear in: $\quad E U R O$

Received date: $\quad$ 2-3-2017

Accepted date: $\quad 14-3-2017$

Please cite this article as: Iles David, Khan Rabia, Naidoo Kristina, Kearney Rohna, Myers Jenny, Reid Fiona.The Impact of Anal Sphincter Injury on Perceived Body Image.European Journal of Obstetrics and Gynecology and Reproductive Biology http://dx.doi.org/10.1016/j.ejogrb.2017.03.024

This is a PDF file of an unedited manuscript that has been accepted for publication. As a service to our customers we are providing this early version of the manuscript. The manuscript will undergo copyediting, typesetting, and review of the resulting proof before it is published in its final form. Please note that during the production process errors may be discovered which could affect the content, and all legal disclaimers that apply to the journal pertain. 


\section{Title}

\section{The Impact of Anal Sphincter Injury on Perceived Body Image}

\section{Authors}

David Iles ${ }^{a}$, Rabia Khan ${ }^{a}$, Kristina Naidoo ${ }^{a}$, Rohna Kearney ${ }^{a}$, Jenny Myers ${ }^{a, b}$, Fiona Reida,b

a. The Warrell Unit, St. Mary's Hospital, Central Manchester University Hospitals NHS Foundation Trust, Manchester Academic Health Science Centre, Manchester, M13 9WL, United Kingdom

b. University Institute of Human Development, Faculty of Medical Human Sciences, University of Manchester, United Kingdom

\section{Corresponding Author Contact Information}

David lles

The Warrell Unit

St. Mary's Hospital

Oxford Road

Manchester

M13 9WL

Telephone: 07854852651

Fax: 01612766085

Email: diles@nhs.net 


\section{Abstract}

\section{Objective}

Obstetric anal sphincter injury is common but the effect on body image is unreported. The aim of this study was to explore patient perceived changes in body image and other psychological aspects in women attending a perineal follow-up clinic.

\section{Study Design}

This retrospective study analysed women's responses to a self-reported questionnaire. Consecutive women with anal sphincter injury who attended a United Kingdom Maternity Hospital perineal followup clinic between January 1999 and January 2012 were identified and the records obtained and reviewed. Multivariate regression analyses were performed to examine variables influencing selfreported change in body image.

\section{Results}

Questionnaires and operation notes were analysed from 422 women who attended at a median of four months after delivery. $222(53 \%)$ reported a change in body image with 80 (19\%) reporting lower self-esteem and 75 (18\%) a change in their personality due to the change in body image. 248 (59\%) perceived an anatomical change due to the delivery. Factors associated with increased likelihood of reporting a change in body image were reporting a perceived change in anatomy due to the delivery, adjusted OR 6.11 (3.56-10.49), anal incontinence, OR 1.97 (1.16-3.36), and delivery by forceps, OR $2.59(1.23-5.43)$.

\section{Conclusions}

This is the first study to quantify body image changes in women after anal sphincter injury sustained in childbirth. These were found to be very common, affecting up to $50 \%$ of women. The study has several limitations but it does highlight the significant psychosocial problems of negative self-esteem and personality changes associated with a perceived change in body image that has not previously been reported. It also outlines the further research questions that need to be addressed. 


\section{Keywords}

Body Image, Anal Sphincter Injury, Perineal Trauma

\section{Introduction}

Anal sphincter injury is common, occurring in up to $6 \%$ of deliveries ${ }^{1,2}$. A range of physical symptoms can occur including bowel symptoms which may range from mild, transient effects to intractable anal incontinence ${ }^{2-4}$. Studies have also described the adverse impact on frequency of sexual activity ${ }^{5-7}$, perineal pain ${ }^{8-11}$ and dyspareunia ${ }^{9-12}$ and a high prevalence of urinary incontinence ${ }^{4}$. However, very few studies have investigated the psychological aspects of anal sphincter injury and none have considered the impact on women's body image.

Body image describes an individual's own concept of their physical appearance. It is dynamic, influenced by attitudes, beliefs, feelings and behaviours ${ }^{13}$ resulting from developmental processes, personality traits and external factors such as trauma and disease, cultural influences and life experiences. The concept of body image dissatisfaction has become recognised as an important factor in medical disorders. It may be a consequence of anatomical disfigurement or physiological dysfunction (e.g. incontinence). It is a complex construct, with dissatisfaction in body image being both an outcome of other processes and also a potentially contributory factor to anxiety, depression, low self-esteem, reduced quality of life ${ }^{13-17}$ or in some cases development of a body image disorder (such as body dysmorphic disorder).

A qualitative study examining women's experiences after anal sphincter injury found body image perception to be an important issue to women ${ }^{18}$. However, there are no studies that have attempted to quantify perception of body image change and the prevalence, duration and the importance of any such change remains unclear.

The aim of this study was to evaluate the perceived change in body image using a symptom questionnaire in women who had sustained an anal sphincter injury. It also aimed to investigate associated factors and physical symptoms recorded at delivery and follow-up. 


\section{Materials and Methods}

This was a retrospective study of consecutive attendees at a United Kingdom Maternity Hospital perineal trauma clinic between the dates of January 1999 and January 2012. Data from women was included if they had sustained a clinically diagnosed anal sphincter tear. Information was collected using a standardised symptom questionnaire completed at the clinic appointment and a clinical proforma which documented the examination findings at the time of repair and the operation notes. The data was obtained during a routine clinical appointment by members of the clinical care team and was fully anonymised prior to analysis. Review of the symptom questionnaire was conducted as part of a service review project and formal ethical review was waived after consultation with local Research Ethics Committee.

Baseline characteristics recorded included: age, parity, previous anal sphincter tears, details about length of labour, pain relief, mode of delivery, birth weight and classification of tear. The St. Mary's Hospital perineal clinic questionnaire was completed. The 66-item questionnaire comprises of symptom questions about the bowel and urinary systems and includes items relating to body image; perceived anatomical changes due to the delivery, effects on partner relationship, sex life and questions about thoughts related to a future pregnancy (annexed information 1).

In this analysis, responses from symptom frequency questions were dichotomised into present or not present. Composite outcomes were formed from questions indicating faecal incontinence and anal incontinence. The outcome of faecal incontinence was created from grouping answers to items indicating involuntary loss of solid or liquid stool (passive or urge faecal incontinence or soiling post defecation). Anal incontinence included the addition of flatal incontinence. Grade of tear was categorised for all cases as a partial or complete tear of the external sphincter; using the estimation of percentage loss of the external anal sphincter musculature which is recorded by the surgeon as standard practice in the operation proforma.

\section{Statistical analysis}

Univariate analysis (Fisher's exact test) and multivariate logistic regression analyses were performed using perceived change in body image as the binary dependent outcome variable. 
This was an exploratory study and as no prior data were available for the prevalence of change in body image post anal sphincter injury a formal sample size calculation was not performed. Data were therefore collected over the maximum time period available. Logistic regression included a maximum of seven variables; the event per variable rate always exceeded 10 .

All statistic tests were two sided and were evaluated at a significance level of $p<0.05$. Statistical analyses were conducted using SPSS (IBM Corp. Released 2011) or STATA (v13.1, StataCorp, TX).

\section{Results}

During the time period studied, 513 women who had sustained an anal sphincter injury attended a primary appointment at the perineal trauma clinic. Data were extracted from the Warrell Unit perineal clinic questionnaire and clinical operation proforma for 422 of these women. Case notes were unavailable or data was incomplete for 91 women and these were excluded. Demographic characteristics and delivery information is shown in table 1.

When asked about body image, $222(53 \%)$ women had perceived a change. 140 (33\%) of women felt less attractive due to this change in body image and $80(19 \%)$ felt it was causing them to have a low self-esteem.

Univariate analyses for the outcome of perceived change in body image and binary psychological variables were performed. Significantly higher numbers of women reporting change in body image reported anxiety regarding future deliveries, either being put off from having another baby (43\% versus $30 \%$, p value 0.009 ), or feeling frightened when contemplating another delivery (68\% versus $51 \%, p$ value $<0.001)$. A higher proportion of women reporting a change in body image also expressed a preference for a future Caesarean delivery ( $36 \%$ versus $26 \%$, p value 0.045 ).

The univariate analyses and frequencies of physical symptom and psychological items in the questionnaire and delivery characteristics are presented as annexed information (annexed information 2). Multiple Logistic regression analysis was performed for the outcome of perceived change in body image. Table 2 shows the odds ratios, 95\% confidence intervals and $p$ values for the covariates investigated. 
After adjustment, women who perceived an anatomical change due to delivery were six times more likely to report body image change. Delivery by forceps was associated with a 2.6 -fold increased risk of a perceived change in body image. A twofold increased risk was seen for women complaining of anal incontinence.

\section{Comment}

This study found that over half the women attending a perineal clinic appointment after an anal sphincter injury reported a perceived change in body image. A third of the women reported feeling less attractive and a fifth reported low self-esteem and change in personality due to body image changes. Following adjustment for other confounding variables, the strongest association for perceived change in body image was a perceived change in anatomy due to the delivery.

To our knowledge, this is the first study which has reported a perceived change in body image after anal sphincter injury. Our findings are therefore informative in providing an assessment of the number of women who have an adverse psychosocial outcome following anal sphincter injury. This is of particular interest as body image has been demonstrated to have an important relationship with selfesteem, depression, sexual function and quality of life in other medical conditions ${ }^{16,17,19-21}$. In addition it has been shown that body image can be improved with counselling techniques ${ }^{22}$.

Body Image is a complicated construct, and it is likely that a complex range of factors can influence dissatisfaction in body image after anal sphincter injury. This could be a consequence of psychological effects after a traumatic birth, altered personal relationships, anatomical consequences and physical pelvic floor symptoms. Also pregnancy may affect women's general body image due to change in breasts, abdominal wall and weight ${ }^{23}$. However, the strong association found between perceived change in anatomy due to delivery and change in body image suggests it may be genital, rather than general body image which is affected. This suggests that the anatomical result of a repaired tear may be crucial. To date, there is no research evaluating the effect of vaginal delivery or perineal tears on genital body image. 
In this study, we observed that symptoms of anal incontinence were strongly associated with an increased risk of a perceived change in body image. Perhaps more surprisingly there was also a strong association with forceps delivery. This observation needs to be validated in future studies, but it is likely that the association of mode of delivery with a perceived change in body image is complex. It was also interesting to note that there appeared to be no increase in a perceived change in body image following ventouse delivery. Vacuum extraction is more likely to fail in vaginal delivery compared to forceps ${ }^{24}$, hence forceps may be chosen in a group of women with an anticipated difficult delivery. The circumstances of the labour or delivery itself may influence body image perception; further exploration of this interaction is necessary to determine whether interventions following instrumental delivery could positively influence body image perception.

Only $22 \%$ of all women in the study were undecided or reported no preference for mode of delivery in a future pregnancy. Although this information was obtained prior to counselling, there may be implications for planning randomised trials related to mode of delivery for women after anal sphincter injury; it is possible that only patient preference trials would be feasible.

The successful treatment of body image dissatisfaction needs to be considerate to the underlying cause $^{25}$. It is likely that perceived change in body image is rarely assessed after anal sphincter injury. Priority is more likely given to an assessment of bowel symptoms and education regarding functional treatments such as pelvic floor exercises. Physical symptom improvement is clearly critical, but this study demonstrates that recognition of other psychosocial issues may also be important. Women may benefit from counselling about body image in the perineal clinic. Cognitive behavioural therapy has been used to treat body image dissatisfaction in other conditions and may be a worthwhile intervention for women after anal sphincter injury. ${ }^{26}$.

Our results support previous findings from qualitative studies which indicate body image to be an issue for women after perineal trauma and anal sphincter injury ${ }^{18,27}$. However, there are significant differences between our population of perineal clinic attendees and other published studies. The prevalence of anal incontinence in our study group was $71 \%$ compared to $23 \%-54 \%^{2-4,28,29}$ in other studies. This is probably due to our pragmatic sampling of women who attended the perineal clinic. All women that sustain an anal sphincter injury are invited to attend the perineal clinic but non-attenders over the study period was $30 \%$. It is possible that women who do not attend their scheduled 
appointment have much lower rates of physical symptoms and psychosocial problems, including body image issues. Additionally, although the median time from delivery to clinic attendance was 4 months, there were 40 women $(9 \%)$ who presented 12 months after delivery who had been referred with symptoms; inclusion of these women has inevitably introduced some bias into the sample. The results cannot therefore be generalised outside a population attending a follow-up clinic after an anal sphincter injury.

There are a number of significant limitations to this study. Data was collected using a standardised symptom questionnaire but this had not been psychometrically validated. Initially there were no validated body image questionnaires available for use. However, since we started data collection a range of specific body image questionnaires have been validated ${ }^{30-32}$. However, to our knowledge, to date, no symptom questionnaires have been validated for use specifically after childbirth in the setting of a perineal trauma clinic.

The study contains a large number of women but unfortunately as a retrospective review of clinical practice it does not have a control group who sustained lesser degrees of perineal trauma. Hence it is not possible compare the change in body image in women who sustained anal sphincter injury to those who sustained other degrees of perineal trauma. Another limitation was the inability to address significant confounding factors, such as depression and anxiety.

Future studies should use validated tools to assess both general and genital body image. It is unknown whether genital body image is more severely affected after childbirth associated with anal sphincter injury than other vaginal births and whether counselling post-delivery can improve genital body image. Future studies should evaluate whether a woman's genital body image returns to prepregnancy level with time, or whether there is a significant impact on postnatal depression or psychosexual disorders.

In conclusion, although this study is only a retrospective review of clinical practice and therefore has several flaws, it does provide information about the incidence of body image changes associated with anal sphincter injury that has not been previously quantified. It has demonstrated that a large number of women, up to $50 \%$, who have sustained an anal sphincter injury during childbirth report a change in body image and this was frequently associated with psychosocial problems of negative self-esteem 
and personality changes. Despite the lack of a control group, the high prevalence of change in body image demonstrated in this study indicates the need for further research in this area.

\section{Condensation}

A large proportion of women attending follow-up after anal sphincter injury report perceived changes in body image with associated negative effects on self-esteem and personality. 


\section{REFERENCES}

1.

Gurol-Urganci I, Cromwell DA, Edozien LC, et al. Third- and fourth-degree perineal tears among primiparous women in England between 2000 and 2012: time trends and risk factors. BJOG. 2013;120(12):1516-1525. doi:10.1111/1471-0528.12363.

Zetterström J, López A, Anzén B, Norman M, Holmström B, Mellgren A. Anal sphincter tears at vaginal delivery: risk factors and clinical outcome of primary repair. Obstet Gynecol. 1999;94(1):21-28. http://www.ncbi.nlm.nih.gov/pubmed/10389712. Accessed February 13, 2014

Borello-France D, Burgio KL, Richter HE, et al. Fecal and urinary incontinence in primiparous women. Obstet Gynecol. 2006;108(4):863-872. doi:10.1097/01.AOG.0000232504.32589.3b.

Tetzschner T, Sørensen M, Lose G, Christiansen J. Anal and urinary incontinence in women with obstetric anal sphincter rupture. Br J Obstet Gynaecol. 1996;103(10):1034-1040. http://www.ncbi.nlm.nih.gov/pubmed/8863705. Accessed January 30, 2014.

Brubaker L, Handa VL, Bradley CS, et al. Sexual function 6 months after first delivery. Obstet Gynecol. 2008;111(5):1040-1044. doi:10.1097/AOG.0b013e318169cdee.

Rådestad I, Olsson A, Nissen E, Rubertsson C. Tears in the vagina, perineum, sphincter ani, and rectum and first sexual intercourse after childbirth: a nationwide follow-up. Birth. 2008;35(2):98-106. doi:10.1111/j.1523-536X.2008.00222.x.

van Brummen HJ, Bruinse HW, van de Pol G, Heintz APM, van der Vaart CH. Which factors determine the sexual function 1 year after childbirth? BJOG. 2006;113(8):914-918. doi:10.1111/j.1471-0528.2006.01017.x.

Andrews V, Thakar R, Sultan AH, Jones PW. Evaluation of postpartum perineal pain and dyspareunia--a prospective study. Eur J Obstet Gynecol Reprod Biol. 2008;137(2):152-156. doi:10.1016/j.ejogrb.2007.06.005.

Haadem K, Ohrlander S, Lingman G. Long-term ailments due to anal sphincter rupture caused by delivery--a hidden problem. Eur J Obstet Gynecol Reprod Biol. 1988;27(1):27-32. http://www.ncbi.nlm.nih.gov/pubmed/3338606.

Palm A, Israelsson L, Bolin M, Danielsson I. Symptoms after obstetric sphincter injuries have little effect on quality of life. Acta Obstet Gynecol Scand. 2013;92(1):109-115. doi:10.1111/j.1600-0412.2012.01532.x.

Sundquist J-C. Long-term outcome after obstetric injury: a retrospective study. Acta Obstet Gynecol Scand. 2012;91(6):715-718. doi:10.1111/j.1600-0412.2012.01398.x.

Signorello LB, Harlow BL, Chekos AK, Repke JT. Postpartum sexual functioning and its relationship to perineal trauma: retrospective cohort study of primiparous women. Am J Obstet Gynecol. 2001;184(5):881-8-90. doi:10.1067/mob.2001.113855.

Cash TF. Body image: past, present, and future. Body Image. 2004;1(1):1-5. doi:10.1016/S1740-1445(03)00011-1.

Stice E, Shaw HE. Role of body dissatisfaction in the onset and maintenance of eating pathology: a synthesis of research findings. J Psychosom Res. 2002;53(5):985-993. http://www.ncbi.nlm.nih.gov/pubmed/12445588. Accessed May 27, 2014.

Sarwer DB, Thompson JK, Cash TF. Body image and obesity in adulthood. Psychiatr Clin North Am. 2005;28(1):69-87, viii. doi:10.1016/j.psc.2004.09.002.

Benrud-Larson LM, Heinberg $\mathrm{L}$, Boling $\mathrm{C}$, et al. Body image dissatisfaction among women with scleroderma: extent and relationship to psychosocial function. Health Psychol. 2003;22(2):130-139. http://www.ncbi.nlm.nih.gov/pubmed/12683733. Accessed May 29, 2014.

Fauerbach JA, Heinberg L, Lawrence JW, et al. Effect of early body image dissatisfaction on subsequent psychological and physical adjustment after disfiguring injury. Psychosom Med. 2000;62(4):576-582. http://www.ncbi.nlm.nih.gov/pubmed/10949104. Accessed May 27, 2014.

Williams A, Lavender T, Richmond DH, Tincello DG. Women's experiences after a third-degree obstetric anal sphincter tear: a qualitative study. Birth. 2005;32(2):129-136. doi:10.1111/j.0730-7659.2005.00356.x.

Orr DA, Reznikoff M, Smith GM. Body image, self-esteem, and depression in burn-injured adolescents and young adults. $J$ Burn Care Rehabil. 1989;10(5):454-461. http://www.ncbi.nlm.nih.gov/pubmed/2793926. Accessed May 29, 2014.

Keskin G, Gumus AB. Turkish hysterectomy and mastectomy patients - depression, body image, sexual problems and spouse relationships. Asian Pac J Cancer Prev. 2011;12(2):425-432. http://www.ncbi.nlm.nih.gov/pubmed/21545207. Accessed May 13, 2014.

Hazewinkel MH, Sprangers MAG, Velden J van der, Burger MPM, Roovers J-PWR. Severe pelvic floor symptoms after cervical cancer treatment are predominantly associated with mental and physical well-being and body image: a cross-sectional study. Int J Gynecol Cancer. 2012;22(1):154-160. doi:10.1097/IGC.0b013e3182332df8.

Veale D, Anson M, Miles S, Pieta M, Costa A, Ellison N. Efficacy of Cognitive Behaviour Therapy versus Anxiety Management for Body Dysmorphic Disorder: A Randomised Controlled Trial. Psychother Psychosom. 2014;83(6):341-353. doi:10.1159/000360740.

Hodgkinson EL, Smith DM, Wittkowski A. Women's experiences of their pregnancy and postpartum body image: a systematic review and meta-synthesis. BMC Pregnancy Childbirth. 2014;14:330. doi:10.1186/1471-2393-14-330.

Johanson RB, Menon BK. Vacuum extraction versus forceps for assisted vaginal delivery. Cochrane database Syst Rev. 2000;(2):CD000224. doi:10.1002/14651858.CD000224

Bolton 004DA, Lobben I, Stern TA. The impact of body image on patient care. Prim Care Companion J Clin Psychiatry. 2010;12(2). doi:10.4088/PCC.10r00947blu.

Rosen JC. The nature of body dysmorphic disorder and treatment with cognitive behavior therapy. Cogn Behav Pract. 
1995;2(1):143-166. doi:10.1016/S1077-7229(05)80008-2.

27. Priddis $\mathrm{H}$, Dahlen $\mathrm{H}$, Schmied V. Women's experiences following severe perineal trauma: a meta-ethnographic synthesis. $J$ Adv Nurs. 2013;69:748-759. doi:10.1111/jan.12005.

28. Fenner DE, Genberg B, Brahma P, Marek L, DeLancey JOL. Fecal and urinary incontinence after vaginal delivery with anal sphincter disruption in an obstetrics unit in the United States. Am J Obstet Gynecol. 2003;189(6):1543-9-50. doi:10.1016/j.ajog.2003.09.030.

29. Poen AC, Felt-Bersma RJ, Strijers RL, Dekker GA, Cuesta MA, Meuwissen SG. Third-degree obstetric perineal tear: long-term clinical and functional results after primary repair. $\mathrm{Br} J$ Surg. 1998;85(10):1433-1438. http://www.ncbi.nlm.nih.gov/pubmed/9782032. Accessed February 24, 2014.

30. Hopwood P, Fletcher I, Lee a, Al Ghazal S. A body image scale for use with cancer patients. Eur J Cancer. 2001;37(2):189-197. http://www.ncbi.nlm.nih.gov/pubmed/23724453.

31. McDermott E, Moloney J, Rafter N, et al. The body image scale: a simple and valid tool for assessing body image dissatisfaction in inflammatory bowel disease. Inflamm Bowel Dis. 2014;20(2):286-290. doi:10.1097/01.MIB.0000438246.68476.c4.

32. Herbenick D, Reece M. Development and validation of the female genital self-image scale. J Sex Med. 2010;7(5):1822-1830. doi:10.1111/j.1743-6109.2010.01728.x. 
Table 1. Demographical and delivery characteristics ${ }^{a, b}$

\begin{tabular}{|c|c|c|}
\hline Variable & $\begin{array}{l}\text { Median or } \\
\text { frequency }\end{array}$ & Number \\
\hline Age at delivery (years) & $29(25-32)$ & 422 \\
\hline Gestation at delivery (completed weeks) & $40(39-41)$ & 408 \\
\hline Length of first stage (minutes) & $425(240-650)$ & 373 \\
\hline Length of second stage (minutes) & $70(30-117)$ & 367 \\
\hline Birthweight (g) & $3500(3180-3890)$ & 410 \\
\hline $\begin{array}{l}\text { Time between delivery and clinic } \\
\text { (months) }\end{array}$ & $4(3-7)$ & 422 \\
\hline Mode of delivery & & \multirow[t]{5}{*}{415} \\
\hline Normal delivery & $279(66 \%)$ & \\
\hline Ventouse Delivery & $54(13 \%)$ & \\
\hline Forceps Delivery & $58(14 \%)$ & \\
\hline Ventouse and Forceps & $24(6 \%)$ & \\
\hline Primiparous (after index delivery) & $315(75 \%)$ & 422 \\
\hline Previous Anal Sphincter Injury & $28(7 \%)$ & 422 \\
\hline $\begin{array}{l}\text { Classification of external anal sphincter } \\
\text { tear }\end{array}$ & & \multirow[t]{3}{*}{376} \\
\hline Complete & $21(6 \%)$ & \\
\hline Partial & $355(84 \%)$ & \\
\hline
\end{tabular}

1. Data are presented as median (interquartile ranges) or frequencies (percentages)

2. Numbers vary due to incomplete data 
Table 2. Adjusted odds ratios ${ }^{a}$ for effects of variables on change in body image ${ }^{b}$

\begin{tabular}{|l|l|l|l|}
\hline Variable & $\begin{array}{l}\text { Odds } \\
\text { Ratio }\end{array}$ & $\mathbf{9 5 \%} \mathbf{~ C l}$ & $\mathbf{p}$ value \\
\hline Delivery by Forceps & 2.59 & $1.23,5.43$ & 0.012 \\
\hline $\begin{array}{l}\text { Perceived change in anatomy due to } \\
\text { delivery }\end{array}$ & 6.11 & $3.56,10.49$ & $<0.001$ \\
\hline Anal incontinence & 1.97 & $1.16,3.36$ & 0.013 \\
\hline Parity & 1.19 & $0.87,1.64$ & 0.273 \\
\hline Dyspareunia & 1.09 & $0.66,1.82$ & 0.727 \\
\hline Stress urinary incontinence & 1.26 & $0.77,2.06$ & 0.365 \\
\hline $\begin{array}{l}\text { Time from delivery until clinic } \\
\text { attendance }\end{array}$ & 1.00 & $0.97,1.04$ & 0.850 \\
\hline
\end{tabular}

1. Each odds ratio is adjusted for all other variables in the table

2. 339 women included in analysis 